\title{
Implementation of Android-Based Vehicle Tracking System in Trac Astra Rent A Car Palembang
}

\section{Implementasi Sistem Tracking Kendaraan Berbasis Android Pada Trac Astra Rent A Car Palembang}

\author{
Irman Effendy ${ }^{1}$, Fatoni ${ }^{2}$ \\ ${ }^{1}$ Program Studi Sistem Informasi, Universitas Bina Darma, Palembang, Indonesia \\ 2Program Studi Teknik Informatika, Universitas Bina Darma, Palembang, Indonesia \\ Email: 1irman_effendy@binadarma.ac.id,2fatoni@binadarma.ac.id
}

\begin{abstract}
TRAC Astra Rent A Car is a leading car rental service provider in Indonesia, which also has a branch in the city of Palembang. Starting with only 5 units of vehicles, now PT. TRAC Astra Rent A Car rental car into a business unit that has more than 12,000 vehicles operating in more than 1,500 corporate customers segment. PT.TRAC help corporate customers improve efficiency in the transportation business and enable them to concentrate on their core business. Besides short-term car rental needs a safe and comfortable can be easily fulfilled because PT.TRAC location very easy to reach. With the development of information technology today, it would need to complete the management PT.TRAC which she rented vehicle with a tracking facility (tracking) the vehicle's location in real-time so that management can monitor the location where the vehicle which she rented was with the development of Android-Based Tracking system.
\end{abstract}

Keywords: Tracking System, Car Rental, Real-Time

\section{PENDAHULUAN}

Menurut techno.okezone.com (2016), jumlah pengguna smartphone di Indonesia mencapai 55 juta pengguna pada tahun 2015, 65,2 juta pengguna pada tahun 2016, dan 74,9 juta pengguna pada tahun 2017. Sedangkan menurut website statista.com (2016), jumlah pangsa pasar OS Android mencapai 74,2\% pada Desember 2015 yang berarti secara kasar ada 46 juta lebih pengguna smartphone dengan sistem operasi Android di Indonesia saat ini [1]. Jumlah ini peneliti yakini akan meningkat terus dari tahun ke tahun dengan semakin terjangkaunya harga perangkat smartphone Android.

Kendaraan bermotor merupakan angkutan atau alat transportasi yang digunakan masyarakat untuk bepergian [2]. Terlebih lagi dilihat dari 
fenomena saat ini, setidaknya sudah banyak keluarga Indonesia yang memiliki kendaraan bermotor paling tidak kendaraan bermotor roda 2. Bagi keluarga Indonesia yang mampu, kendaraan bermotor roda 4 menjadi pilihan yang memudahkan untuk bepergi an dengan seluruh anggota keluarga, dan saat ini masyarakat lebih memilih kendara an yang nyaman dan efisien dan pilihan masyarakat tertuju pada kendaraan mobil pribadi. Namun tidak semua keluarga memiliki mobil pribadi dikarenakan harga nya yang kurang terjangkau untuk semua lapisan masyarakat. Untuk mengatasi hal tersebut maka hadirlah jasa penyewaan mobil atau yang biasa disebut dengan rental mobil.

TRAC Astra Rent A Car adalah perusahaan penyedia jasa sewa mobil terdepan di Indonesia yang juga mempunyai cabang di Kota Palembang. Bermula dengan hanya 5-unit kendaraan, kini PT. TRAC Astra Rent A Car menjadi unit usaha sewa mobil yang memiliki lebih dari 12.000 kendaraan yang beroperasi di lebih dari 1.500 pelanggan segmen korporat. PT.TRAC membantu pelanggan korporat meningkatkan efisiensi dalam transportasi bisnisnya, dan membuat mereka mampu berkonsentrasi pada bisnis inti [3]. Selain itu kebutuhan sewa mobil jangka pendek yang aman dan nyaman dapat dengan mudah terpenuhi karena lokasi PT.TRAC yang sangat mudah dijangkau. Dengan perkembangan teknologi informasi saat ini, perlu kiranya pihak manajemen PT.TRAC melengkapi kendaraan yang disewakannya dengan fasilitas pelacakan (tracking) lokasi kendaraan secara real-time sehingga pihakmanajemen setiap saat dapat memantau dimana lokasi kendaraan yang disewakannya berada.

\section{METODOLOGI}

Untuk melakukan implementasi sistem tracking kendaraan berbasis android pada Trac Astra Rent a Car Palembang maka digunakan berbagai metode yaitu metode penelitian untuk menjelaskan hasil penelitian dan metode pengembangan yang digunakan untuk proses pengembangan. berikut dapat dijelaskan metode penelitian dan pengembangan tersebut.

\subsection{Metode Penelitian}

Dalam melakukan peneltian implementasi sistem tracking kendaraan berbasis android pada Trac Astra Rent a Aar Palembang ini metode yang digunakan untuk menjelaskan hasil peneltian menggunakan teknik atau metode deskriptif. Dalam banya penelitian dijelaskan bahwa metode ini merupakan metode yang digunakan untuk menjelasakan fakta dan penomena sebuah objek yang diteliti berdasarkan pandangan peneliti [4]. Dapat juga dikatakan bahwa metode penelitian dekkriptif merupakan paparan sebuah kedaan fakta yang diteliti berdasarkan perspektif peneliti [5]. 


\subsection{Metode Pengembangan}

Metode pengembangan sistem yang digunakan dalam penelitian ini adalah metode prototyping. Langkah-langkah yang diperlukan dalam siklus pengembangan suatu aplikasi untuk membangun dan mengimplementasikan suatu aplikasi di perusahaan dengan digunakan pengembangan aplikasi dan sistem e-business yang dapat memenuhi kebutuhan bisnis perusahaan, karyawan dan pihak-pihak yang berkepentingan terhadap perusahaan (stakeholder).

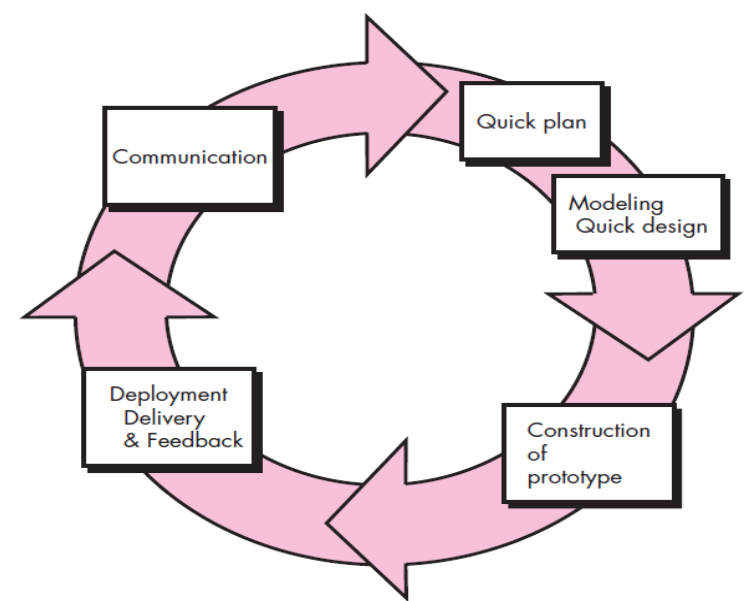

Gambar 1. Siklus Hidup Metode Prototyping [6]

Dari Gambar 1 dapat dijelaskan masing-masing tahapan dalam Prototyping adalah sebagai berikut [7]:

a) Komunikasi, Pelanggan dan pengembang bersama-sama mendefinisikan format seluruh perangkat lunak, mengidentifikasikan semua kebutuhan, dan garis besar sistem yang akan dibuat.

b) Perencanaan Secara Cepat, Pengembang membuat perencanaan mengenai prototype yang akan dibuat yang berfokus pada penyajian kepada pelanggan (misalnya dengan membuat imput dan format output).

c) Perancangan Secara Cepat, Pengembang membuat rancangan prototype yang berfokus pada keinginan pelanggan.

d) Pembuatan Prototype, Dalam tahap ini prototyping yang sudah disepakati diterjemahkan ke dalam bahasa pemrograman yang sesuai/dikehendaki

e) Penyebaran, Pengujian dan Umpan Balik, Setelah sistem sudah menjadi suatu perangkat lunak yang siap pakai, harus dites dahulu sebelum digunakan. Pengujian ini dilakukan dengan White Box, Black Box, Basis Path, pengujian arsitektur dan lain-lain. Pelanggan mengevaluasi apakah sistem yang sudah jadi sudah sesuai dengan yang diharapkan . Jika ya, tahapan selesai, jika tidak, ulangi dari langkah 1, 2, 3 
atau 4. Perangkat lunak yang telah diuji dan diterima pelanggan siap untuk digunakan.

Untuk menggunakan metode prototyping dalam proses pengembagnan maka terdapat tiga pendekatan utama prototyping, yaitu:

a) Throw-Away, Prototype dibuat dan dites. Pengalaman yang diperoleh dari pembuatan prototype digunakan untuk membuat produk akhir (final), kemudian prototype tersebut dibuang (tak dipakai).

b) Incremental, Produk finalnya dibuat sebagai komponen-komponen yang terpisah. Desain produk finalnya secara keseluruhan haya ada satu tetapi dibagi dalam komonen-komponen lebih kecil yang terpisah (independent).

c) Evolutionary, Pada metode ini, prototype-nya tidak dibuang tetapi digunakan untuk iteraksi desain berikutnya. Dalam hal ini, sistem atau produk yang sebenarnya dipandang sebagai evolusi dari versi awal yang sangat terbatas menuju produk final atau produk akhir.

\section{HASIL DAN PEMBAHASAN}

\subsection{Pemodelan Aplikasi}

Pemodelan aplikasi merupakan proses awal ketika proses pengembangan dilakukan. Pemodelan digunakan untuk memudahkan pengembang dalam proes pengembangan awal aplikasi. Dalam melakukan pemodelan digunakan unified modeling language (UML).UML merupakan kumpulan diagram yang mampu untuk menggambarkan bagaiaman sebuah aplikasi dibentuk [8]. Di dalam penelitian ini digunakan tiga diagram untuk menggambarkan aplikasi yang dibuat yaitu use case diagram, activity diagram dan class diagram. Gambar 2 dapat dilihat merupakan use case diagram aplikasi.

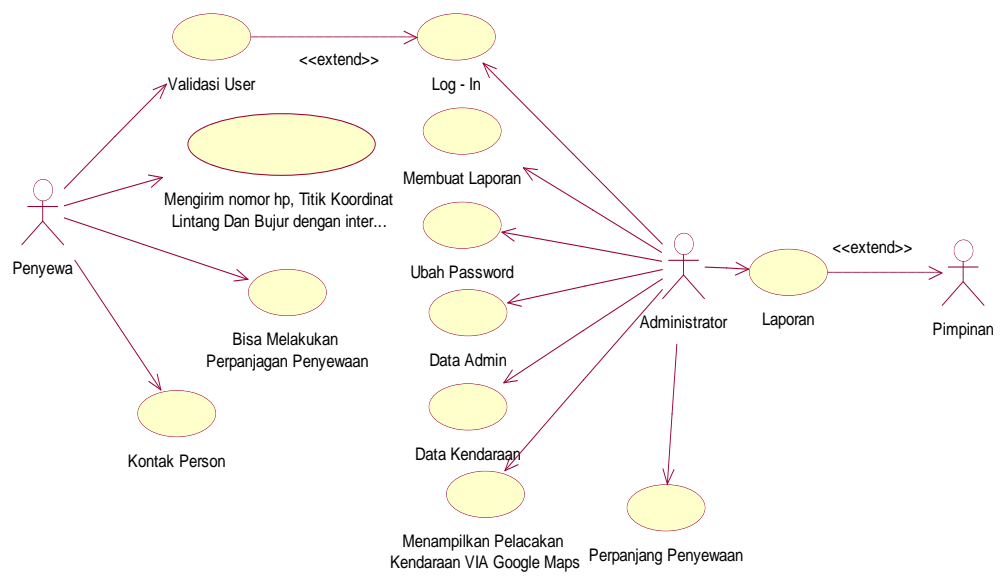

Gambar 2. Use Case Diagram 
Gambar 2 dapat diketahui merupakan use case diagram untuk aplikasi. Use case diagram merupakan diagram yang menggambarkan bagaimana tingkah laku dari aplikasi yang akan dibuat [9]. Tingkah laku yang digambarkan merupakan tingkah laku dari aplikasi dan pengguna yang berinteraksi. Pada Gambar 2 dapat diketahui bahwa terdapat tiga aktor yang berinteraksi yaitu penyewa, administrator aplikasi dan pimpinan. Dimana masing-masing aktor memiliki use case masing-masing. Selain use case diagram digambarkan juga activity diagram yang digunakan untuk menggambarkan bagaimana masing-masing aktor melakukan aktivitasnya di dalam aplikasi [10]. Gambar 3 merupakan activity diagram aplikasi. Pada Gambar 3 dapat dilihat untuk melakukan aktivitas semua aktor harus melakukan login, dianljutkan melakkukan aktivitas seperti membuka aplikasi, mengisi formulir penyewaan dan melakukan perpanjangan. Selanjutnya admin dapat melakukan validasi data dan memproses data. Sedangkan pimpinan dapat melihat laporan aktivitas penyewaan.

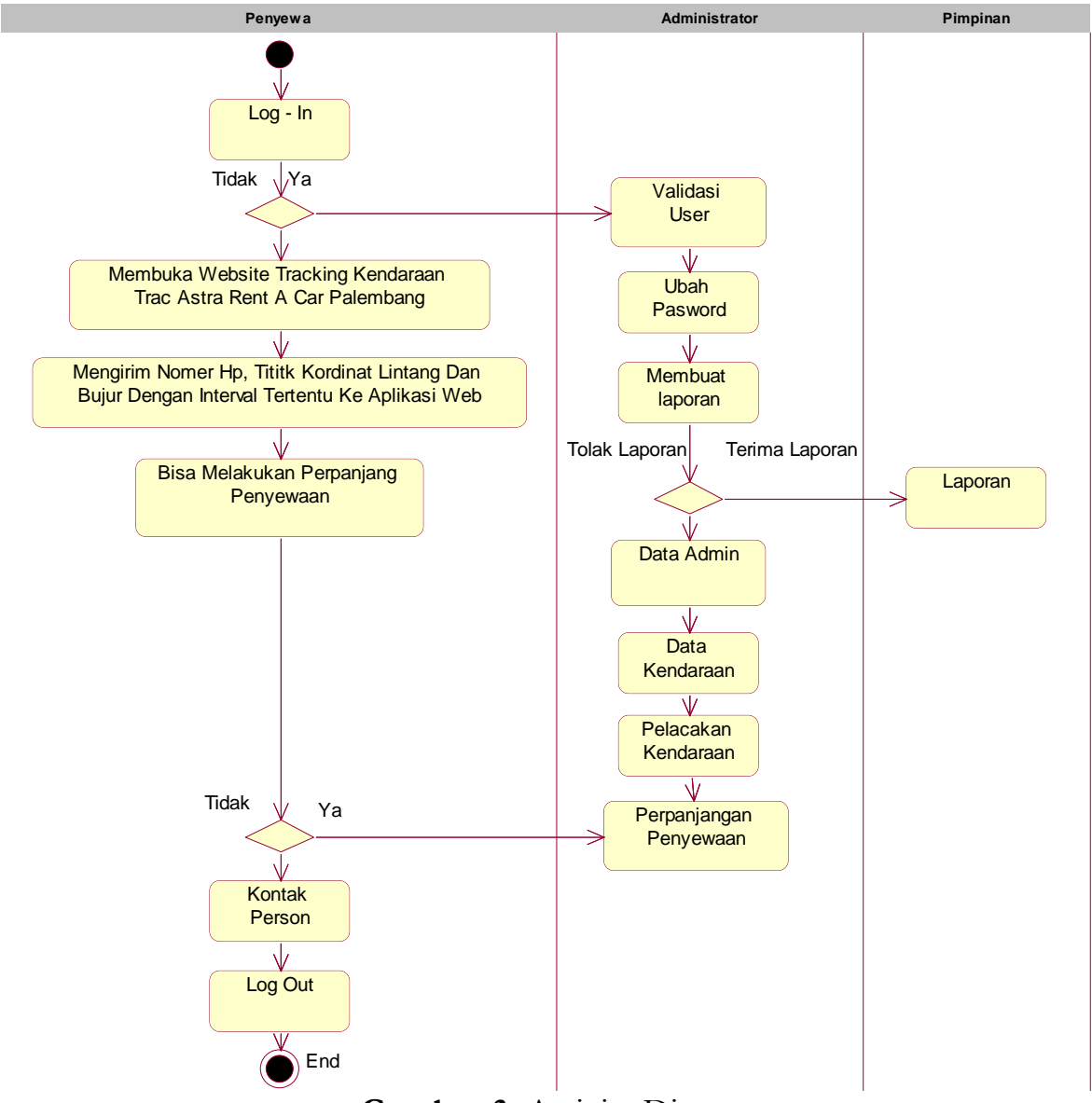

Gambar 3. Activity Diagram 
Vol. 2, No. 1, March 2020

p-ISSN: 2656-5935 http://journal-isi.org/index.php/isi

e-ISSN: 2656-4882

Selanjutnya yaitu class diagram, class diagram merupakan salah satu dari jenis structure diagram yang ada di dalam diagram UML. Structure diagram biasanya diperuntukkan untuk melihat strukur pembentuk aplikasi yang dilihat dari masing-masing elemen yang ada pada aplikasi [11]. Gambar 4 merupakan class diagram untuk aplikasi. Dari Gambar 4 dapat diketahui ada empat pembentuk utama dari aplikasi yaitu admin, kendaraan, tracking, dan perpanjang waktu.

\begin{tabular}{|c|c|c|c|}
\hline Admin & \multirow{3}{*}{\begin{tabular}{|l} 
Kendaraan \\
\$no_polisi : string \\
\$nama_kendaraan : string \\
\$warna: string \\
\$no_mesin : string \\
\$kap_penumpang: integer \\
\$kap_barang : decimal
\end{tabular}} & Tracking & \multirow{4}{*}{ 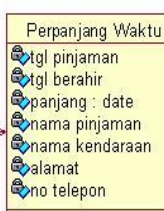 } \\
\hline $\begin{array}{l}\text { Boid_admin : string } \\
\text { 8nama_admin : string } \\
\text { 8)Password : string } \\
\text { \&ulabatan : string }\end{array}$ & & $\begin{array}{l}\text { QDid_tracking : Integer } \\
\text { \$ono_polisi : string } \\
\text { 8waktu: Date } \\
\text { \$olintang: doble }\end{array}$ & \\
\hline \multirow{3}{*}{$\begin{array}{l}\text { Insert0 } \\
\text { Select0 } \\
\text { Update0 } \\
\text { Delete0 }\end{array}$} & & & \\
\hline & \multirow{2}{*}{ 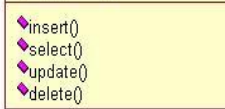 } & \multirow{2}{*}{ 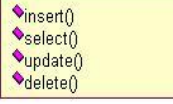 } & \\
\hline & & & \\
\hline
\end{tabular}

Gambar 4. Class Diagram

\subsection{Hasil Pemodelan Aplikasi}

Setelah melakukan pemodelan aplikasi dan melakukan pembuatan aplikasi berdasarkan saran dan perbaikan yang diingkan pengguna untuk memenuhi kebutuhan pengguna maka dapat dilihat pada Gambar 5 merupakan tampilan awal dari aplikasi yang dihasilkan. Pada sisi kanan pada Gambar lima merupakan tampilan awal ketika aplikasi dibuka, dimana pengguna diminta untuk memasukkan nomor kendaraan atau nomor polisi dari kendaraan yang akan dilakukan tracking. Setelah memasukkan nomor polisi maka akan ditampil menu untuk melakukan tracking seperti yang diperlihatkan pada Gambar 5 sebelah kanan. Terdapat dua menu yaitu aktifkan track dan stop track.

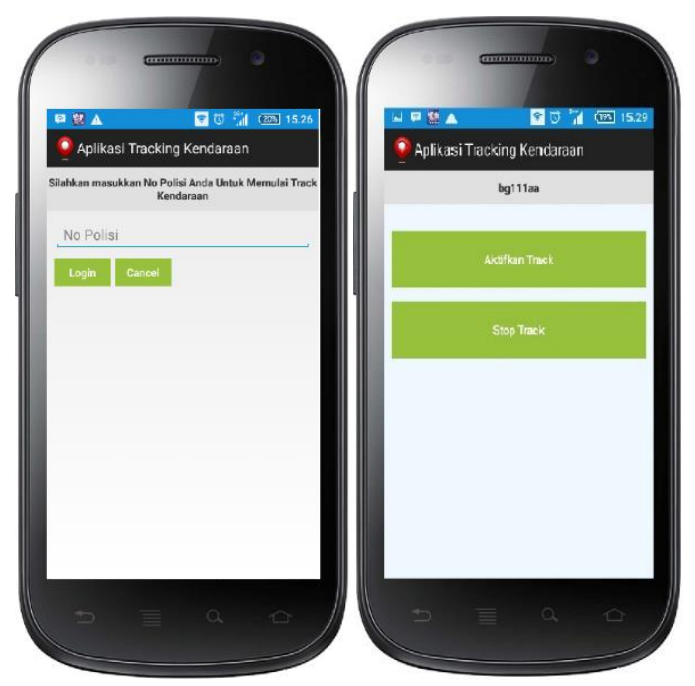

Gambar 5. Tampilan Awal Aplikasi 
Selain untuk melakukan tracking yang dapat dilakukan oleh admin terdapat juga menu yang dikhususkan untuk penyewa, untuk mengakses menu ini penyewa harus melakukan login terlebih darhulu, dan kemudian akan ditampilkan halaman khusus untuk penyewa. Pada halaman penyewa terdapat tiga menu utama yaitu perpanjangan sewa, info sewa dan logout. Untuk melakukan perpanjangan penyewaan maka penyewa dapat melakukan klik menu perpanjangan sewa maka akan ditampilkan form pengisian jumlah hari perpanjangan sewa. Pada Gambar 6 dapat dilihat proses perpanjangan sewa.

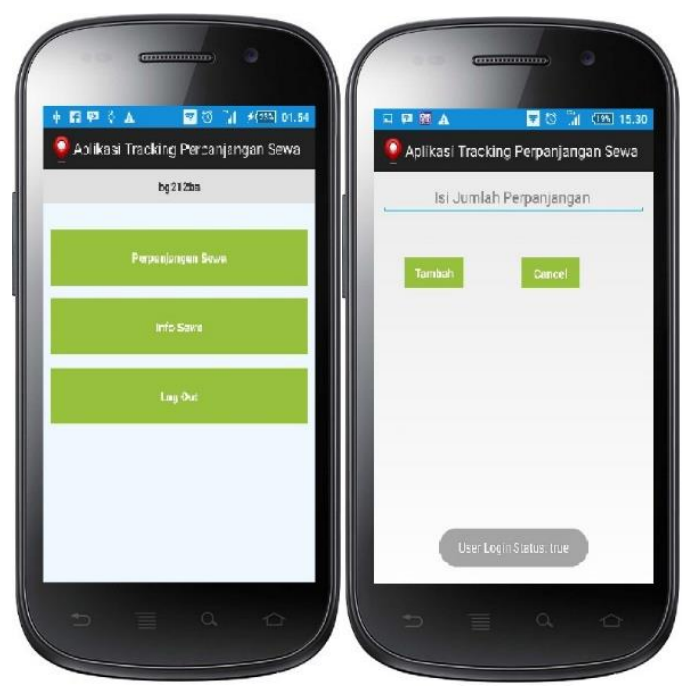

Gambar 6. Perpanjangan Sewa

Untuk melakukan monitoring data dan pelaporan pada aplikasi tracking maka dilakukan melalui antarmuka berbasis web. Penggunaan antarmuka berbasis web disebabkan agar memudahkan dalam melihat informasi dan lebih mudah untuk dioperasikan oleh admin dan juga pimpinan. Proses monitoring dan pelaporan data tersebut seperti yang diperlihatkan pada Gambar 7.

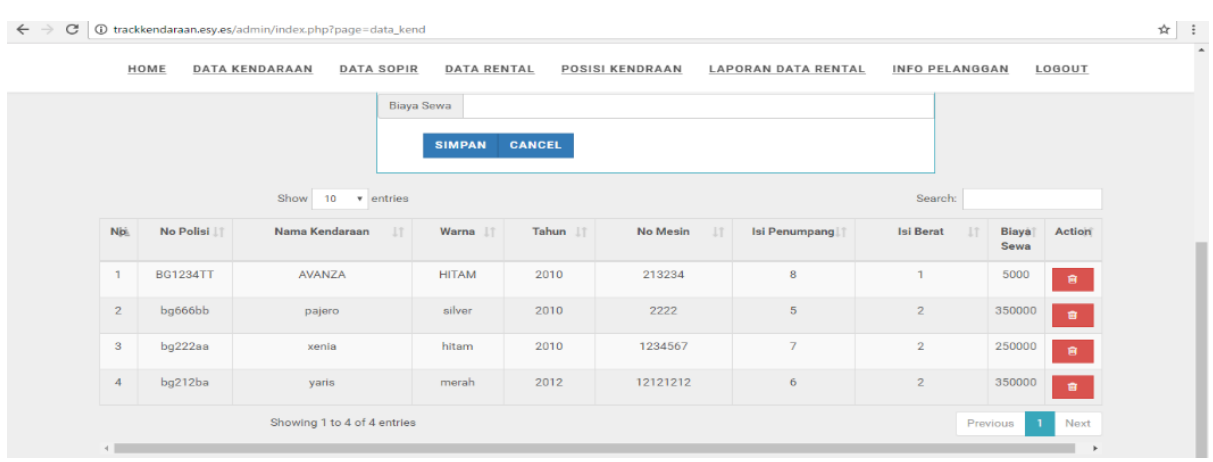

Gambar 7. Antarmuka Berbasis Web 


\section{KESIMPULAN}

Sesuai dengan uraian yang telah dikemukakan berkaitan dengan pengembangan aplikasi tracking pada TRAC Astra Rent A Car Palembang yang dikembangkan berbasis android maka dapat disimpulkan beberapa hal yaitu: (1) aplikasi tracking berbasis android dapat digunakan TRAC Astra Rent A Car Palembang dalam memberikan dan menyampaikan informasi kepada pelanggan karena aplikasi telah dikembangkan sesuai dengan kebutuhan yang pengguna yand dapat dibuktikan dari pemodelan aplikasi. (2) aplikasi tracking berbasis android ini diharapkan dapat memudahkan TRAC Astra Rent A Car Palembang dalam pengelolaan data penyewa. (3) Dengan adanya aplikasi tracking berbasis android dapat membantu dan memudahkan pihak TRAC Astra Rent A Car Palembang dalam melakukan evaluasi ataupun pemantauan dalam memantau tracking kenadaraan yang disewa oleh pelanggan.

\section{REFERENSI}

[1] APJII, "Indonesia Internet Service Provider Association: Penetrasi dan Perilaku Pengguna Internet Indonesia,” Jakarta, 2018.

[2] D. Ritonga, J. A. Timboeleng, and O. H. Kaseke, "Analisa Biaya Transportasi Angkutan Umum Dalam Kota Manado Akibat Kemacetan Lalu Lintas (Studi Kasus: Angkutan Umum Trayek Pusat Kota 45Malalayang)," J. Sipil Statik, vol. 3, no. 1, 2015.

[3] A. F. Annisa, "The Influence of Compensation and Work Environment to Employee Performance with Job Satisfaction as Intervening Variable at Trac Astra Rent a Car Yogyakarta Branch,” 2017.

[4] S. Suyanto and U. Ependi, "Pengujian Usability dengan Teknik System Usability Scale pada Test Engine Try Out Sertifikasi," MATRIK J. Manajemen, Tek. Inform. dan Rekayasa Komput., vol. 19, no. 1, pp. 62-69, 2019.

[5] I. Effendy and A. M. Bakti, "INTEGRASI SMART ATTENDANCE BAGI DOSEN SEBAGAI UPAYA PENINGKATAN KINERJA," KLIK-KUMPULAN J. ILMU Komput., vol. 6, no. 3, pp. 317-326, 2019.

[6] N. Huda, "Website Sistem Informasi Desa Sungai Rebo Banyuasin Sumatera Selatan," Konf. Nas. Sist. Inf. 2018, 2018.

[7] R. Rusdiansyah, "Membangun Prototype Sistem Informasi Arsip Elektronik Surat Perjanjian Kerjasama Pada Business Support Departement," J. Pilar Nusa Mandiri, vol. 14, no. 2, pp. 157-162, 2018.

[8] N. Oktaviani and S. Sauda, "Pemodelan dan Implementasi Aplikasi Mobile Umrah Guide Menggunakan Unified Modeling Language," J. Sains dan Inform., vol. 5, no. 2, pp. 177-186, 2019.

[9] A. Syazili, F. Fatoni, and R. Sutejo, "Pemodelan dan Implementasi Perangkat Lunak Berbasis Mobile pada Bina Darma TV," JISKA Jurnal 
Inform. Sunan Kalijaga), vol. 3, no. 3, pp. 62-69, 2019.

[10] S. Sauda, N. Oktaviani, and M. Bunyamin, "Implementasi Metode Scrum Dalam Pengembangan Test Engine Try Out Sertifikasi," JISKA Jumal Inform. Sunan Kalijaga), vol. 3, no. 3, pp. 70-78, 2019.

[11] S. D. Purnamasari and F. Panjaitan, "PEMODELAN SISTEM INFORMASI SEBARAN PASAR MENGGUNAKAN UNIFIED MODELING LANGUAGE," JIPI Jurnal I lm. Penelit. dan Pembelajaran Inform., vol. 4, no. 2, pp. 103-110, 2019. 